\title{
Familia adoptiva y cambios en la organización familiar tradicional
}

\section{José Ocón Domingo}

Universidad de Granada. Facultad de Ciencias Políticas y Sociología

C/Rector López Argüeta, s/n. 18071 Granada

joseocon@ugr.es

\section{Resumen}

Con este trabajo informamos de la influencia que los cambios sociales ocurridos en las últimas décadas en España han tenido sobre la organización familiar tradicional, dando cabida a otras nuevas formas familiares. Obviando otros modelos familiares, profundizamos en el devenir histórico experimentado por la adopción y, en consecuencia, por la familia adoptiva, subrayando las modificaciones observadas en sus distintas características. Finalmente, desde la óptica del interés del men15or, se vierten algunas reflexiones sobre la conveniencia de la nueva familia homosexual, dado que la posibilidad de matrimonio y adopción homosexual están suscitando una gran controversia en la sociedad española.

Palabras clave: devenir histórico, nuevas formas familiares, familia adoptiva, familia homosexual adoptiva.

\section{Abstract. Adoptive family and the changes in the traditional family organization}

In this paper we want to address the influence that the social changes occurring in the latest decades have in the traditional family organization, and the appearance of new family configurations. Not considering other familiar models, we will focus on the historic development of adoption, and in consequence of the adoptive family. Finally, from the point of view of the children interest, we will introduce some thoughts about the convenience of the new homosexual family, taking in account that the marrying and adopting possibilities are creating an important controversy in the Spanish society.

Key words: historic development, new family configurations, adoptive family, homosexual family.

\section{Sumario}

Introducción La familia homosexual adoptiva

Nuevas formas familiares

Conclusiones

El devenir de la familia adoptiva

Bibliografía 


\section{Introducción}

De todas las investigaciones que abordan el tema de la familia se deriva una consecuencia ineludible: la importancia que históricamente viene teniendo esta institución en cualquier tipo de sociedad. Incluso en las sociedades desarrolladas, la familia continúa considerándose como la unidad imprescindible en tareas relacionadas con la reproducción social y con la satisfacción de las principales necesidades del ser humano: socialización, educación, regulación sexual, protección afectivo-emocional y apoyo económico de sus miembros. Por éstas y otras razones, el grupo familiar está considerado como el referente imprescindible, más intenso y persistente de la vida emocional de los individuos.

Este conjunto de circunstancias hace que se mantenga como una institución muy bien valorada. Así se manifestaba en una encuesta de Eurobarómetro (1993), que reflejaba cómo un 95,7\% de los ciudadanos de la Unión Europea seguía considerando a la familia como un hecho muy importante de sus vidas, por delante del trabajo $(90,2 \%)$, de los amigos y conocidos $(88,3 \%)$ y del ocio (84,3\%) (Meil, 1999: 16). Y es que, al margen de la etapa histórica y del entorno sociocultural que se analice, siempre ha resultado invariable la existencia de alguna forma de articular el parentesco y las relaciones entre los individuos. De este modo figura en el artículo 16.3 de la Declaración Universal de los Derechos Humanos de 1948: «La familia es el elemento natural y fundamental de la sociedad y tiene derecho a la protección de la sociedad y del Estado». Sin embargo, como señala Eurostat, el gasto en políticas de protección de la familia y la infancia en España es de los más bajos de la Unión Europea de los Quince. En el año 1999, sólo se dedicaba el $0,4 \%$ de su producto interior bruto (PIB), mientras que en la Unión Europea llegaba al 2,3\% (Damon, 2004). Pero, pese a su permanencia, esta institución también se ha ido modificando conforme a la dinámica social y en paralelo a otras realidades socioculturales.

Estas modificaciones en los valores, la creencias, las actitudes y las costumbres sociales se han venido mostrando muy relevantes en España con el devenir democrático y en diferentes esferas sociales. De ahí que el ideal de familia tradicional o patriarcal católica, entendida como un proyecto de convivencia con carácter público e indisoluble, centrada en el matrimonio heterosexual y con una división en el tema de los roles y de las decisiones en función del sexo, pese a continuar como referente, haya evolucionado hacia un modelo no tan bien delimitado y cada vez más privatizado, más democrático y susceptible de ruptura. Esta mayor igualdad, además de en diversos ámbitos de la vida social, se observa en varias esferas de la vida familiar: ejercicio del poder, protagonismo de la mujer en el presupuesto económico, participación paterna en el cuidado y la atención de los hijos, redistribución de las tareas domésticas, etc.

Una encuesta a cargo del CIS (2004a) abunda en estos aspectos. En torno a la forma ideal de familia, el 68\% de los entrevistados se inclina por aquella en que hombre y mujer trabajen fuera de casa y se repartan las tareas del hogar y el cuidado de los hijos, así como el 56\% cree en la discusión democrática como la mejor solución de las dificultades que pudieran surgir entre padres e hijos. 


\section{Nuevas formas familiares}

Pero, como adelantamos, la manifestación más palpable viene representada por la convivencia de un mayor abanico de modelos de organización familiar, por otra parte, dotados de características propias. Y es que la familia a que se refiere nuestra Carta Magna, entendida como núcleo de relaciones personales y afectivas, alberga múltiples formas de convivencia que no se restringen a las matrimoniales. "Por tanto, la familia en los albores del siglo XXI, ya no es la de antaño ni las normas jurídicas pueden ser las mismas. Una sociedad plural basada en relaciones de igualdad y libertad dan lugar a muy diversas formas de relaciones familiares, todas ellas válidas y aceptadas por el derecho» (Alberdi, 1995: 382). Del texto se desprende una referencia a las familias monoparentales, a las uniones de hecho, a las familias reconstituidas y a las homosexuales.

Sin embargo, del análisis histórico o antropológico se desprende una consecuencia irrefutable: la existencia, más o menos remota en términos temporales, de las ahora denominadas «nuevas formas familiares». Pero, si no se repara en ciertas connotaciones, este concepto puede resultar bastante confuso. La pertinencia del mismo, siguiendo al profesor Ruiz Becerril (2004: 220-221), resulta de las siguientes peculiaridades:

1. Origen. La mayoría de estas realidades familiares han surgido históricamente como consecuencia de acontecimientos externos o imprevistos, fundamentalmente por la muerte de uno de los miembros de la pareja. Actualmente, como componente decisivo, se aprecia cómo en la mayoría de las ocasiones responden a un deseo consciente, voluntario y expreso de la pareja.

2. Extensión social. Además de su mayor representación estadística, estas familias están presentes en los diferentes sectores sociales. De ello se deduce que los criterios de pertenencia a una clase social o edad de los actores no implican necesariamente la inclusión o exclusión de una determinada forma de familia.

3. Extensión cuantitativa. Su presencia numérica y proporcional alcanza en la actualidad cotas muy alejadas de periodos históricos anteriores.

4. Concepción viable. Estas nuevas familias son formas que ahora se conciben con capacidad de mantenerse por sí mismas, así como factibles y permanentes a la hora de establecer una relación y de cumplir con las funciones asignadas tradicionalmente a la familia. No se entienden, pues, bajo el prisma de formas residuales de otra familia y/o con una probabilidad de permanencia temporal limitada o reducida.

5. Reconocimiento y legitimación social y legal. Estas nuevas formas familiares no comprenden la diferencia con las familias tradicionales en cuanto a derechos y deberes, por lo que reclaman un tratamiento igualitario.

6. Publicidad. Si en el pasado se mantenían en el ámbito privado y oculto, por el contrario, ahora se aceptan con normalidad. Esta tolerancia es fundamental para aquéllas que quieran legitimarse y consolidar progresivamente su presencia. 
7. Diversidad de los ciclos vitales. En las sociedades actuales se ha dinamitado el carácter unilineal propio de las personas y las familias clásicas. De modo que han desaparecido los ciclos vitales fijos y se recoge la posibilidad de casi infinitas opciones a la hora de configurarlos, y estas circunstancias se han extendido a todos los agentes sociales.

Sin embargo, la familia homosexual adoptiva resulta especialmente novedosa. Su inexistencia histórica, la singularidad de los actores implicados en estos procesos tan particulares y, en su conjunto, los elementos ideológicos que comporta son de tal envergadura, que las muy recientes posibilidades de matrimonio y de adopción abiertas a estas parejas han puesto de manifiesto la división de opiniones que se vienen gestando en la sociedad española. Dado que la adopción es una de las vías para acceder a este modelo de familia y, al objeto de una mayor comprensión, hemos decido dedicar el siguiente apartado a la familia adoptiva. Posteriormente se abordará en profundidad la familia homoparental adoptiva.

\section{El devenir de la familia adoptiva}

Pese a que cada uno de los nuevos modelos familiares sería merecedor de un examen más extenso, por cuestiones obvias, hemos decidido posponerlo para otra ocasión. Y es que, frente al resto de organizaciones familiares, tanto el recurso de la adopción en sí mismo considerado, como estas familias, vienen recibiendo por los autores un tratamiento que se nos antoja bastante escaso. En muchas ocasiones, incluso resultan excluidas del catálogo reservado a las nuevas formas familiares. De ahí que nuestro propósito consista ahora en justificar el cumplimiento de todos y cada uno de los requisitos más arriba señalados. Esta forma de proceder, además de brindarnos la posibilidad de sugerir algunos conocimientos adicionales sobre ella, alerta de las dificultades que se presentan a la hora de proporcionar una definición suficientemente exhaustiva y comprensiva de familia, y de proceder a una delimitación precisa de las «nuevas formas familiares».

\section{Orígenes y evolución histórica}

Los antecedentes de la adopción informan de la antigüedad que reviste la familia adoptiva ${ }^{1}$. Durante el Imperio romano, tenía como objetivos básicos la perpetuación del linaje familiar y la transmisión del patrimonio, así como los de asegurar el culto a los ancestros y elevar al adoptado a un nivel civil superior de patricio o ciudadano (Chemin, 1974).

1. Ya se contemplaba en el Código de Hammurabi, hace cerca de cuatro mil años, así como era practicada por los antiguos israelitas y en diversas ciudades griegas (Rodrígues, 1997). Por otra parte, Kadushin (1980) y Parrondo (2001) anotan que la primera adopción registrada es la historia del nacimiento de Sargón I, fundador de Babilonia en el siglo XVIII antes de Cristo. 
Las invasiones bárbaras hicieron que, en torno al año 500 después de Cristo, se contara con dos clases de adopciones: la plena y la menos plena. La primera, que incorporaba totalmente al adoptado a su familia, tenía lugar cuando el adoptante era un ascendiente del adoptado. Por otra parte, cuando se confiaba el adoptado a una persona ajena a su círculo familiar, conservando su situación familiar anterior y sin quedar sujeto a la patria potestas del adoptante, se producía la adopción menos plena (Manaï, 1990).

Estas manifestaciones, fruto todavía de la ausencia de un sentimiento de infancia, hicieron que en la edad media los niños permanecieran en una situación de verdadero abandono. Por ello, bajo un supuesto cuidado y educación, una de las formas que encontraban los padres para esquivarlos era la entrega a otras familias en adopción (De Mause, 1982). Esta medida continuará persiguiendo la continuación de la estirpe familiar y la herencia o el patrimonio de cargos públicos (Rodrígues, 1997; Chavanneau de Gore, 1992; Castón y Ocón, 2002).

En los siglos que delimitan la edad moderna (XVI y XVII) mantendrá los objetivos del periodo anterior, si bien parece que la adopción no fue muy utilizada por la costumbre tan extendida de recluir a las personas en todo tipo de centros de naturaleza asistencial-benéfica: hospitales, asilos, etc. (Carmona, 1988). No obstante, ya se perciben algunos cambios de relevancia en las relaciones internas de la familia con el niño, al asumir esta institución funciones de orden moral y espiritual (Ariès, 1987).

Estos cambios serán más visibles durante el periodo ilustrado, siendo en el siglo XVIII cuando se produce una separación entre la familia y la sociedad imprescindible para el cultivo de una vida familiar privada entre padres e hijos y, con ella, para el afloramiento de nuevas relaciones familiares (Ariès, 1987). La Ilustración descubre a los niños como un grupo social y como los constructores de la sociedad futura, aunque todavía no albergan los derechos reservados a los adultos (López Méndez, 1995). De ahí que existieran dos modalidades básicas de adopción: una legalista, ante escribano público y testigos (ordinaria), y otra informal (la más común), por medio de la cual un ama «se queda con el niño hasta que lo pidan» (Álvarez Santaló, 1980: 104-105).

Pese a que el siglo XIX representa la continuación de las medidas adoptadas durante el siglo anterior, ya se observa un cierto afán por conducir a los niños por el buen camino, y este celo explica la necesidad de la aparición del Estado protector (De Mause, 1982). Bajo estos presupuestos, la familia se convierte en una institución socializadora básica para que el niño haga suyos los contenidos de su cultura, lo que posibilita la configuración definitiva del sentimiento de infancia (Ariès, 1987). No obstante, como reflejaba la legislación de la época, aún sigue manteniéndose una imagen de la infancia como colectivo dependiente y con rasgos todavía de corte benéfico-asistencial.

El despegue definitivo de la infancia, como un grupo con características y necesidades propias susceptible de una protección especial por parte de la sociedad y del Estado, se producirá en España en torno a los años ochenta, concretamente a partir de la Constitución española de 1978 y de la Ley 1/1987, 
de 11 de noviembre ${ }^{2}$ (denominada Nueva Ley de Adopción). Esta protección recibirá un posterior impulso con la aprobación de la actual Ley 1/1996, de 15 de enero, de Protección Jurídica del Menor ${ }^{3}$.

Estas modificaciones en la concepción de la protección han trasladado los intereses del terreno de los adultos al de los niños. Es el niño el único que tiene derecho a la adopción, y no cualquier niño, sino uno particular y adecuado. Tampoco cualquier persona será considerada apta para convertirse en madre o padre adoptivo. Ahora no se trata de encontrar una vía para dar continuidad a las herencias, a los apellidos o al culto doméstico, ni de rellenar los huecos dejados por un hijo que se ha perdido. Estas motivaciones no son, por sí mismas, válidas para fundar una familia adoptiva, sino aquellas relacionadas con la necesidad y el deseo consciente de los aspirantes de querer convertirse en padres y cumplir con sus obligaciones.

\section{Extensión social y cuantitativa}

La metamorfosis experimentada por la adopción está haciendo que estas familias se vayan desprendiendo de la compañía de un conjunto de estigmas propios del pasado. Esta nueva actitud social, junto a las bajas tasas de fecundidad y de natalidad provocadas por una serie de factores de índole sociocultural, ha otorgado a este recurso una sorprendente expansión social y cuantitativa. La adopción ya no es una realidad propia de familias sin descendencia y de un determinado nivel socioeconómico y cultural.

Además, si tenemos en cuenta que en España pueden adoptar las personas individualmente, los matrimonios, las parejas de hecho heterosexuales y, en algunas comunidades autónomas, también las de hecho homosexuales, nos encontramos en condiciones de afirmar que este recurso, como ha ocurrido con la sociedad española, también se ha ido democratizando.

Las estadísticas disponibles sobre la adopción en España informan de esta gran extensión, sobre todo con motivo del auge alcanzado por la adopción internacional, que fue la responsable del $80 \%$ de las adopciones formalizadas en el año 2004. El incremento de la adopción internacional en España, entre los años 1997 y 2004, ha sido de un 488,21\%. Las 5.541 adopciones formalizadas en este último año convierten a España, tras Estados Unidos, en el segundo país del mundo en adoptar internacionalmente. De modo que esta característica común a las «nuevas formas familiares» también es un requisito satisfecho por la familia adoptiva. Esta evolución puede deducirse de los datos que se recogen en el cuadro 1 .

2. BOE., n. ${ }^{\circ} 275$, de 17 de noviembre.

3. BOE., n. ${ }^{\circ} 15$, de 17 de enero. 
Cuadro 1. Adopciones internacionales por continentes. Período 1997-2004.

\begin{tabular}{lrrrrrrrr}
\hline Continentes & 1997 & 1998 & 1999 & $\mathbf{2 0 0 0}$ & $\mathbf{2 0 0 1}$ & $\mathbf{2 0 0 2}$ & 2003 & $\mathbf{2 0 0 4}$ \\
\hline América Latina & 631 & 960 & 895 & 905 & 721 & 593 & 679 & 585 \\
Asia & 214 & 295 & 443 & 686 & 1.107 & 1.586 & 1.196 & 2.577 \\
Europa del Este & 97 & 216 & 645 & 1.439 & 1.569 & 1.395 & 1.913 & 2.111 \\
África & 0 & 16 & 23 & 32 & 31 & 51 & 163 & 268 \\
\hline Totales & $\mathbf{9 4 2}$ & $\mathbf{1 . 4 8 7}$ & $\mathbf{2 . 0 0 6}$ & $\mathbf{3 . 0 6 2}$ & $\mathbf{3 . 4 2 8}$ & $\mathbf{3 . 6 2 5}$ & 3.951 & 5.541 \\
\hline
\end{tabular}

Fuente: para datos entre 1997 y 2001, consulados españoles en el extranjero (citado por la Subdirección General del Acción Social, del Menor y de la Familia, 2001: 73). Los correspondientes al periodo 2002-2004, han sido recogidos de A. Agulló (2005: 5). Elaboración propia.

\section{Concepción de viabilidad}

La capacidad de estas familias para valerse por sí mismas y de cumplir con las funciones propias de cualquier núcleo familiar es otra de las características de las nuevas formas familiares y, como tal, una realidad suficientemente respaldada por las investigaciones sobre la adopción. Esta faceta se muestra sumamente relevante si consideramos los handicaps que, frente a las restantes formas familiares, han de afrontar estos núcleos familiares: edad de los niños, abandonos, maltratos, acogimientos familiares previos, etc.

Las escasas investigaciones sobre este tema en España ${ }^{4}$, en su conjunto, señalan cómo la adopción es un recurso muy adecuado y satisfactorio para los niños carentes de un ambiente familiar. Esta capacidad se demuestra cuando, tras un periodo razonable de convivencia del adoptado en su nuevo entorno, la evaluación de las áreas física, psicológica y social informa de una destacada y más que saludable superación de los problemas iniciales, y de una razonable integración sociofamiliar y escolar.

\section{Reconocimiento social y legitimación legal}

La familia adoptiva también recibe en los tiempos actuales el mismo reconocimiento y legitimación legal que las familias tradicionales. Al contrario que en etapas previas, en que estas organizaciones familiares eran estigmatizadas socialmente, ahora se percibe un creciente grado de aceptación social. Incluso,

4. Por orden cronológico, pueden consultarse: P. AMORÓs (1987): La adopción y el acogimiento familiar, Barcelona, Narcea; Martí X. MARCH (1993): La adopción en Mallorca. Una investigación evaluativa, Palma de Mallorca, Universidad de las Islas Baleares, Consejería de Gobernación y Dirección General de la Juventud, Menor y Familia; J. PALACIOS y otros (1997): La adopción en Andalucía, Sevilla, Junta de Andalucía, Consejería de Asuntos Sociales; J. OCÓN DOMINGo (2003): Aspectos psicosociales de la adopción en Andalucía (una aproximación socio-histórica y jurídico-administrativa), Departamento de Sociología, Facultad de Ciencias Políticas y Sociología, Universidad de Granada, tesis doctoral aún no publicada. 
por las diversas connotaciones y capacidades que comporta, el estatus familiar alcanzado se percibe por algunos como una decisión a imitar y como un factor de orgullo y de prestigio social. Así lo expresan claramente unos padres adoptivos que fueron entrevistados, con motivo de una investigación, por el autor de este trabajo (Ocón, 2003):

Madre: Ahora, en este momento, sí es positiva. Ahora yo he notado una evolución grande en estos últimos cinco años. [...] Aquí, en España, ha sido el boom y a todo el mundo le gustaría ya imitarla. Era una cosa que estaba ahí, mal vista, que lo hacía un puñado de gente muy particular, y que no, pero ahora está muy bien aceptada.

Padre: Pero la gente lo dice sin complejo [que ha adoptado], lo dice, hasta yo diría con cierto motivo de orgullo. Y recibes, además, por parte del que le llega la noticia, pues una aprobación y un signo de admiración.

Este reconocimiento social se muestra en distintas regulaciones, que han ido otorgando los mismos derechos y protección social a la familia e hijos del modelo tradicional que a la fundamentada en otras connotaciones. Del artículo 14 de nuestra Carta Magna no se desprende ninguna diferenciación, ni tampoco del artículo 39.2, que recoge: «Los poderes públicos asegurarán la protección integral de los hijos, iguales éstos ante la ley con independencia de su filiación, y de las madres, cualquiera que sea su estado civil [...]».

De modo que se cuenta con la Ley 11/1981, de 13 de mayo, que modifica la filiación, la patria potestad y el régimen económico del matrimonio, y suprime la antigua distinción entre filiación legítima e ilegítima. Es decir, que regula la equiparación total de los hijos ante la ley con independencia de que la filiación se haya producido por naturaleza o adopción. Esta igualdad también ha quedado reflejada en la instrucción de 15 de febrero de 1999, de la Dirección General de los Registros y del Notariado, por la que se modifica el procedimiento de registro de un niño adoptado. Supone que en el asiento de inscripción del Registro Civil se haga constar como padres únicamente a los adoptivos, sin ninguna mención al carácter de «adoptivos» de los hijos. También la Ley 39/1999, de 5 de noviembre, de conciliación de la vida laboral y familiar, establece los mismos derechos de los padres, tanto biológicos como adoptivos, a un permiso por maternidad, al disfrute de una excedencia y a la nulidad del despido por motivos relacionados con la paternidad o la maternidad.

\section{Publicidad y diversidad de ciclos vitales}

Los reconocimientos recibidos por la familia adoptiva están haciendo que su existencia se vaya desarrollando al margen del oscurantismo y secretismo tradicionales, que alcanzaban a familiares, amigos, vecinos y a los propios hijos. El conocimiento de los antecedentes y del estatus de adoptado (que se conoce por «revelación»), hoy está considerado como un elemento crucial del proceso adoptivo. De modo que los especialistas, valorando su importancia para el 
adecuado desarrollo de la identidad del menor ${ }^{5}$, muestran acuerdo en comunicar esta información por razones de orden moral, psicológico y material (Amorós, 1987; Giberti, 1981; Fuertes y Amorós, 1996).

Así, pues, la familia adoptiva está pasando en pocos años del anonimato tradicional a convertirse en un asunto estrella y de considerable relevancia social, siendo por todos conocida su alta presencia en los distintos medios de comunicación. Esta apertura, en suma, refleja el reconocimiento de su capacidad para cumplir con las distintas funciones y obligaciones de cualquier organización familiar. Finalmente, hay poco que añadir en lo relativo a los ciclos vitales, pues no encontramos diferencia alguna con los dinamismos propios de otras formas familiares.

\section{La familia homosexual adoptiva}

La inexistencia histórica de estas familias las hace especialmente novedosas, dado que se ha carecido de un modelo social ni siquiera de connotaciones similares. Ahora si, como se presume, el matrimonio entre homosexuales se implanta en la sociedad española, la adopción por estos cónyuges podría convertirse en una realidad palpable y de gran trascendencia social.

Pese a esta novedad, son bastantes las naciones que regulan legalmente las uniones civiles entre homosexuales, si bien no llegan a suponer la igualación de derechos y obligaciones derivadas del matrimonio. Los países del norte de Europa han sido pioneros en este tipo de uniones: Dinamarca (1989), Noruega (1993), Suecia (1995), Islandia (1996) y Finlandia (2001). Aunque el alcance de derechos en torno a las pensiones, herencia, divorcio, nacionalidad y otros aspectos son variables, en ningún caso permiten la adopción.

En España, la inexistencia de una ley nacional de parejas de hecho (aunque la mayoría de las comunidades autónomas sí la han regulado), ha hecho que sean tres las leyes en este ámbito que extiendan a las parejas homosexuales el derecho a la adopción conjunta que tienen reconocido los matrimonios y las de hecho heterosexuales ${ }^{6}$. Nos referimos a Navarra, País Vasco y Aragón. Concretamente, en la Ley Foral 6/2000, de 3 de julio, «para la igualdad jurídica de parejas estables» de Navarra ${ }^{7}$, se puede leer: «los miembros de la pareja estable podrán adoptar de forma conjunta con iguales derechos y deberes que las parejas unidas por matrimonio».

No obstante, la primera manifestación trascendente en España fue la aprobación por el Congreso de los Diputados, el 29 de junio de 2004, de una pro-

5. Este derecho, entre otras normativas, está recogido en la Declaración de las Naciones Unidas sobre los Principios Sociales y Jurídicos Relacionados con la Protección y Bienestar de los Niños, con especial referencia a la Adopción y a la Colocación en Hogares de Guarda, en los planos Nacional e Internacional, de 1986 (art. 9); o en el Convenio de La Haya de Derecho Internacional Privado de 1993, en materia de adopción internacional (arts. 16, 30 y 31).

6. Reconocido por la Ley $21 / 1987$, de 11 de noviembre.

7. BON, n. ${ }^{\circ} 82$, de 7 de julio. 
posición no de ley a cargo del PSOE solicitando la plena equiparación legal del matrimonio homosexual con el heterosexual. La propuesta, a excepción del PP, recibió el respaldo de todos los grupos parlamentarios. Posteriormente, el 1 de octubre, se ha procedido a la aprobación del anteproyecto de ley que generaliza todos los derechos del matrimonio heterosexual al homosexual, incluido el de adopción. La norma definitiva, que con toda probabilidad será un hecho en el año 2005, convierte a España en el tercer país de Europa y del mundo en regular nacionalmente la institución matrimonial homosexual, tras Holanda (2000) y Bélgica (2003). En el continente americano, además del Estado de Massachusetts (EE.UU.), el matrimonio del mismo sexo está permitido en Canadá (2003), aunque sólo en el territorio de Yukon y en las provincias de Ontario, Quebec, Nueva Escocia, Manitoba y Columbia Británica.

Con independencia de las posibilidades brindadas por la legislación española, quizás el planteamiento a realizar desde una perspectiva psicológica y social deba centrarse en discernir la capacidad real de estas familias para satisfacer las necesidades de los niños. También han de tenerse en cuenta, por su impacto sobre el menor, las reacciones sociales que pudieran cosecharse. Al respecto, un estudio del Centro de Investigaciones Sociológicas (2004b), señala que el $67,7 \%$ de los encuestados considera que las parejas estables del mismo sexo deben tener los mismos derechos y obligaciones que las heterosexuales, así como el 66,2\% son partidarios del matrimonio entre homosexuales. En cuanto a la adopción por homosexuales, el 48,2\% está «muy o bastante de acuerdo", mientras que el $44,1 \%$ se muestra "poco o nada de acuerdo".

Sin embargo, según las investigaciones nacionales e internacionales, este recurso se viene concibiendo muy conveniente para los niños sin una familia. Y estas bondades alcanzan su máxima expresión cuando se contrastan con los efectos negativos que pueden provocar las institucionalizaciones ${ }^{8}$. Uno de los estudios referidos, desarrollado en Andalucía por J. Palacios y otros (1997), subraya que los niños adoptados obtienen puntuaciones muy similares a sus compañeros de clase en las distintas áreas estudiadas. Por el contrario, los niños en centros de protección obtienen los peores resultados en hostilidad y agresividad, ansiedad y temores, hiperactividad y distracción, autoestima, rendimiento escolar y en problemas y malestares psicosomáticos. Por otra parte, la presencia de parejas homosexuales que desean formar una familia y de otras que ya disponen de ella, al contar con hijos nacidos de relaciones heterosexuales previas, por inseminación artificial o por vía de la adopción individual, constituye una realidad palpable en la sociedad española y su incremento parece incuestionable.

Pese a la existencia de distintas posiciones, en principio podría considerarse que esta opción reduciría el número de niños carentes de un ambiente fami-

8. Un recorrido histórico en torno a la institucionalización y sus efectos puede consultarse en J. OCón (2000): «Pasado y presente de las instituciones de acogida para menores en España: un análisis particular de la Comunidad Autónoma de Andalucía», Revista del Ministerio de Trabajo y Asuntos Sociales, n. ${ }^{\circ}$ 25: 79-94. 
liar. Sobre todo si consideramos que muchos de ellos, por sus características especiales (deficiencia física, psíquica, enfermedad, etnia, edad, etc.), son poco demandados por los adoptantes. Estas circunstancias harían que estuvieran destinados a permanecer de por vida en algún tipo de institución. En definitiva, desde esta posición psicosocial, nos atreveríamos a afirmar que las resistencias sociales en esta materia pueden agruparse en torno a las siguientes consideraciones fundamentales.

En primer lugar, además de muchas carencias, los niños susceptibles de adopción suelen tener una singular experiencia de abandonos, maltratos, abusos sexuales, internamientos, acogimientos diversos, etc. En este sentido, la orientación homosexual de los padres adoptivos supondría una diferencia adicional y, probablemente, un incremento del sufrimiento y de la discriminación de estos niños.

Se podrían encontrar, en segundo lugar, inconvenientes relacionados con el papel socializador de la familia, sobre todo con el aprendizaje de los roles de género. Ahora las personas se podrían oponer a estas adopciones por las consecuencias que podrían derivarse de esta modalidad de convivencia, así como por el recelo a que los hijos pudieran seguir la orientación sexual de los padres $\mathrm{y}$ «caer» en la homosexualidad.

Relacionado con estas cuestiones, en tercer lugar, nos inclinamos por destacar el referente que supone una sociedad dominada por un modelo de conducta heterosexual y bajo unas formas de familia que, si bien hoy diversos, son ciertamente diferentes al homosexual. Es decir, el temor de algunos a los efectos surgidos de estas experiencias familiares, fruto del permanente contraste de las circunstancias del adoptado con las de otras personas del entorno. Ahora se enfatizaría en las repercusiones psicológicas derivadas de comentarios y preguntas de corte similar a la siguiente: "¿Quién es tu mamá y quién tu papá?».

Sin embargo, con cierta independencia del peso de las razones anteriores, parece que existe evidencia suficiente sobre el correcto desarrollo de los niños criados en una familia homosexual ${ }^{9}$. Los estudios llevados a cabo en Estados Unidos, según Herrero Brasas (1993), no han mostrado ningún efecto negativo, ni incremento alguno de la orientación homosexual. En este sentido, dice Gilgoff (2004: 4) que, tras tres décadas de investigación sociológica en Estados Unidos, la Asociación de Psicología Americana, la Academia de Pediatras

9. La Asamblea Parlamentaria del Consejo de Europa (26-10-2000) ha recomendado a los gobiernos de los países miembros que adopten medidas para poner fin a la discriminación que padecen los homosexuales. Esta indicación se ha apoyado en el estudio de un informe titulado Situación de las lesbianas y los gays en los estados del Consejo de Europa, redactado por el parlamentario húngaro Csaba Tabadji, que recoge la falta de constancia para establecer diferencias en el desarrollo psicosocial de niños educados en el seno de familias heterosexuales y homosexuales. Con relación a este aspecto, también puede consultarse el trabajo a cargo de Julie Danielle KUNIN (1998), «Predictors of psychosocial and behavioral adjustment of children: A study comparing children raised by lesbian parents to children raised by heterosexual parents», Dissertation Abstract Internacional, section B: The Sciences \& Engineering, vol. 59 (6-B), 3094. 
Estadounidense, la Asociación Nacional de Asistentes Sociales y la Asociación de Abogados Estadounidenses han aprobado públicamente la paternidad gay. También recoge una afirmación de Judith Stacey, catedrática de Sociología, Género y Sexualidad de la Universidad de Nueva York: «No hay un solo estudio que haya hallado diferencias [entre los niños de padres gays y de padres heterosexuales] que puedan interpretarse como perjudiciales». Un avance de los resultados globales del único estudio realizado en Francia —en forma de tesis doctoral - sobre una muestra de 58 niños criados por padres homosexuales, discurre en esta dirección. Su autora, Nadaud (2002: 302), adelanta:

No se trata, pues, de afirmar que todos los niños de padres homosexuales van bien, sino de aportar una piedra suplementaria al edificio de los estudios que ya muestran que los comportamientos corresponden a los de otros niños de su edad.

También en España se cuenta con un único estudio, realizado en la Universidad de Sevilla (2002) bajo la dirección de la profesora Mar González. Sus conclusiones alertan de que no pueden establecerse distinciones apreciables en el desarrollo personal de los menores criados en familias homoparentales y heteroparentales. En cualquier caso, se observa una mayor apertura de aquellos menores a la hora de considerar los roles de género y las distintas opciones de orientación sexual (Sánchez-Mellado, 2004).

Pese a la necesidad de una mayor y más completa investigación, la cuestión se centraría en otros aspectos, y no tanto en debates ideológico-jurídicos sobre la necesidad de extender estos derechos a todos los ciudadanos. Como anotamos, cuando se toma una decisión de carácter protector, el niño se convierte en sujeto único de derecho. Lo fundamental estribaría en la capacidad de tolerancia, flexibilidad, control emocional, etc., que en realidad constituyen los basamentos imprescindibles para la debida crianza y atención a los niños. Así lo indica el profesor Palacios $(2000)^{10}$ :

Son muchas las parejas y las personas que pueden responder a estas exigencias de la adopción. Lo esencial no radica en sus creencias religiosas, en sus preferencias sexuales o en su forma de organización familiar, sino en sus actitudes educativas y en su capacidad para hacer frente adecuada y establemente a las necesidades de quienes son adoptados.

En este sentido, si somos conscientes de estos resultados y de la importante labor en tareas relacionadas con la selección, formación, asignación de un menor y seguimiento de la familia adoptiva, que tienen encomendadas los equipos profesionales al servicio de la Administración, estas reticencias sociales podrían minusvalorarse. El seguimiento de la familia adoptiva, tanto hete-

10. En un artículo titulado «El supremo derecho de los niños a una infancia feliz», El País, 24 de septiembre de 2000 . 
rosexual como homosexual, sigue cobrando una importancia fundamental. Es, sin duda, la mejor forma de aspirar al mayor bienestar del niño y a la felicidad de la unidad familiar en su conjunto.

\section{Conclusiones}

Las características que revisten las familias adoptivas, como las restantes nuevas formas familiares, suponen un reflejo adicional de los cambios y de las tendencias sociales. Así ha ocurrido con otros temas polémicos en torno a la inseminación artificial, al aborto, al divorcio, etc., que hoy forman parte de la realidad. En lo que respecta a la adopción en general y, en particular, a la controversia sobre el matrimonio y la adopción homosexual, si bien se necesita un mayor acopio de estudios, la evidencia destaca las bondades atribuidas a este recurso. Además, cuando la patria potestad es compartida, los beneficiados siempre son los niños. Respecto a la adopción internacional y, a fin de dar cabida a los procesos de adopción homosexual, la adaptación de la normativa de los países de origen de los niños es capital. Los efectos positivos de la adopción, frente a las condiciones que soportan estos niños en las instituciones, fueron transmitidos claramente al autor de este trabajo por una madre que formalizó una adopción internacional. Pese a ello, sus palabras no quedan exentas de matizaciones:

Había una frase, me acabo de acordar, allí en la entrada del Instituto Colombiano de Bienestar Familiar, que decía: «La peor de las madres es preferible a la mejor de las instituciones».

En el supuesto de que el matrimonio homosexual y el derecho a la adopción llegaran a plasmarse en España y en otros países, el incremento de estas nuevas formas de familia y las posibilidades de investigación irán determinando las adaptaciones legales y sociales necesarias para mejorar este recurso de protección. Junto a esta modalidad adoptiva, todavía quedan en España algunas cuestiones pendientes relacionadas con la conveniencia (o no) de la denominada «adopción abierta», que permite el contacto entre las familias biológica y adoptiva, y con los niños nacidos de las denominadas «madres de alquiler». En definitiva, al margen de otros intereses de corte ideológico-partidista, la Administración debe promocionar la investigación y dotarse de los recursos materiales y humanos necesarios para lograr la mayor protección y bienestar de los niños.

\section{Bibliografía}

Agulló, A. (2005). «Récord de las adopciones internacionales». 20 Minutos, p. 5. Alberdi, I. (1995). "Organización formal. Marco legal de la familia». En: AlBERDI, I. (dir.). Informe sobre la situación de la familia en España. Madrid: Ministerio de Asuntos Sociales.

Álvarez Santaló, L.C. (1980): Marginación social y mentalidad en Andalucía occidental. Expósitos en Sevilla (1813-1910). Sevilla: Consejería de Cultura de la Junta de Andalucía. 
AMORÓs, P. (1987). La adopción y el acogimiento familiar. Barcelona: Narcea.

ARIÈs, Ph. (1987). El niño y la vida familiar en el Antiguo Régimen. Madrid: Taurus. CARMONA GARCÍA, J.I. (1988). «La asistencia social en la España de los austrias». En: VV. AA. De la beneficencia al bienestar social. Madrid: Siglo XXI.

CASTÓN, P.; OCÓN, J. (2002). «Historia y sociología de la adopción en España». Revista Internacional de Sociología, n. ${ }^{\circ} 33$, tercera época, p. 173-209.

ChavanNEAU DE GORE, S. (1992). «Adopción: un silencio en la historia». En: GiberTI, E.; Chavanneau De Gore, S. Adopción y silencios. Buenos Aires: Sudamericana.

Chemin, B. (1974). «Aperçus socio-juridiques sur l'Adoption» Bourdeaux Médicale, n. ${ }^{\circ}$ 5, p. $439-446$.

CIS (2004a). Datos de opinión, n. ${ }^{\circ}$ 34, enero-abril. Madrid.

- (2004b). Barómetro de junio, estudio n. ${ }^{\circ}$ 2.568. Madrid.

Convención de las Naciones Unidas sobre los Derechos del Niño, de 20 de noviembre de 1989.

Convenio Relativo a la Protección del Niño y a la Cooperación en Materia de Adopción Internacional. La Haya, 1993.

DAMON, J. (2004). «Les politiques familiales en Europa: convergences y divergences». Les Cahiers Français, n. ${ }^{\circ}$ 322, p. 88-94.

Fuertes, J.; Amorós, P. (1996). «Práctica de la adopción». En: De PAul OChOtORENA, J.; ARRUABARRENA, M.I. (coords.). Manual de protección infantil. Barcelona: Masson.

Herrero Brasas, J.A. (1993). «La sociedad gay: una invisible minoría». Claves de Razón Práctica, n. ${ }^{\circ}$ 36, p. 26-42.

Giberti, E. (1981). La adopción. Padres adoptantes, hijos adoptivos, los otros. Buenos Aires: El Cid.

Gilgoff, D. (2004). «Hijos de un solo sexo». El País, 30 de mayo, p. 5.

Kadushin, A. (1980). Child Welfare Services. Nueva York: McMillan.

Kunin, J.D. (1998). «Predictors of psychosocial and behavioral adjustment of children: A study comparing children raised by lesbian parents to children raised by heterosexual parents». Dissertation Abstract International, section B: The Sciences \& Engirneering, vol. 59 (6-B), 3094.

Ley 21/1987, de 11 de noviembre, por la que se modifican determinados artículos del Código Civil y de la Ley de Enjuiciamiento Civil en materia de adopción.

Ley Orgánica 1/1996, de 15 de enero, de protección jurídica del menor, de modificación parcial del Código Civil y de la Ley de enjuiciamiento civil.

Ley 18/1999, de 18 de mayo, de modificación del artículo 9, apartado 5, del Código Civil.

LÓPEZ MÉNDEZ, E. (1995). «La política social con la infancia». En GuARDA VARGAS y otros (coords.). Avances en política social. Granada: Diputación Provincial.

MANAÏ, D. (1990). «La dispense de consentement en matière d'adoption: autonomie individuelle et contrôle social». Déviance et Societé, n. ${ }^{\circ}$ 3, p. 275-294.

MARCH CERDÁ, M.X. (1993). La adopción en Mallorca. Una investigación evaluativa. Palma de Mallorca: Universidad de las Islas Baleares. Consejería de Gobernación y Dirección General de Juventud, Menor y Familia.

MAUSE, Lloyd de (1982). Historia de la infancia. Madrid: Alianza.

MeIL, G. (1999). La postmodernización de la familia española. Madrid: Acento.

NADAUD, S. (2002). Homoparentalité. Une nouvelle chance pour la famille. París: Fayard. OCÓN DOMingO, J. (2000). «Pasado y presente de las instituciones de acogida de menores en España: un análisis particular de la CC. AA. de Andalucía». Revista del Ministerio de Trabajo y Asuntos Sociales, n. ${ }^{\circ}$ 25, p. 79-94. 
- (2003). Aspectos psicosociales de la adopción en Andalucía (Una aproximación sociohistórica y juridico-administrativa). Granada: Universidad de Granada. Facultad de Ciencias Políticas y Sociología. Departamento de Sociología. Tesis doctoral.

Palacios y otros (1997). La adopción en Andalucía. Sevilla: Consejería de Asuntos Sociales. Dirección General de Atención al Niño.

PARrondo, L. (2001). Adoptar: otra forma de ser padres. Barcelona: Diagonal.

Resolución del Consejo de Europa (77) 33 sobre el acogimiento de menores, de 3 de noviembre de 1977.

Rodrigues, A. (1997). "A adopçao: um antes; e depois?». Infancia e Juventude, n. ${ }^{2}$, p. $31-70$.

Ruiz BECERril, D. (2004). «Nuevas formas familiares». Revista Portularia, vol. 4, p. 219-229.

SÁnChez Mellado, L. (2004). "Queremos casarnos». El País Semanal, n. ${ }^{\circ}$ 1.434, p. $40-50$.

Subdirección General de Programas de Servicios Sociales (2001). Estadística básica de protección a la infancia, boletín n. ${ }^{0}$ 4. Madrid: Ministerio de Trabajo y Asuntos Sociales. Dirección General de Acción Social, del Menor y de la Familia. 